\title{
Use of the Equivalent Mining Height Method for Understanding Overlying Strata Movement and Stress Distribution in an Isolated Coal Pillar
}

\author{
Yang Chen $\left(\mathbb{D},{ }^{1}\right.$ Dong Li $\left(\mathbb{D},{ }^{2}\right.$ Fuxing Jiang, ${ }^{1}$ Lili Zhang, ${ }^{3}$ Cunwen Wang, ${ }^{4}$ and Sitao Zhu ${ }^{1}$ \\ ${ }^{1}$ Civil and Resource Engineering School, University of Science and Technology Beijing, Beijing 100083, China \\ ${ }^{2}$ Safety Engineering College, North China Institute of Science and Technology, Beijing 101601, China \\ ${ }^{3}$ Department of Building Engineering, Zibo Vocational Institute, Zibo, Shandong 255314, China \\ ${ }^{4}$ Research Center for Rock Burst Control, Shandong Energy Group Co., Ltd., Jinan, Shandong 250014, China \\ Correspondence should be addressed to Dong Li; lidong20150041@163.com
}

Received 11 July 2020; Revised 20 August 2020; Accepted 13 September 2020; Published 10 October 2020

Academic Editor: Qing Ma

Copyright (c) 2020 Yang Chen et al. This is an open access article distributed under the Creative Commons Attribution License, which permits unrestricted use, distribution, and reproduction in any medium, provided the original work is properly cited.

In order to study the changing rules of displacement filed and stress field of overlying strata on isolated pillar with filling mining method, a self-designed model of isolated pillar with an equivalent mining height and a monitoring system of stress is employed to study the progressive failure of overlying strata and the changing rules of induced displacement and stress, as the equivalent mining height increases. The findings from the trial tests show the following: (1) When the equivalent mining height is small, the overlying strata on the isolated coal pillar only bend and subside, but the overlying strata located on the goafs of two sides remain stable. (2) As the equivalent mining height increases, the degree of stress concentration on section coal pillar will rise and produce plastic failure in the first place near large caving goaf. The strata can subside between isolated working face and adjacent large caving goaf. (3) As the equivalent mining height increases further, new cracks in the roof of isolated working face will unite the cracks of carving goaf on two sides in horizontal direction, leading to a significant rise of the height of cracks. Three goafs will evolve into a large carving goaf, and the vertical cracks on the outer side of the carving goaf intersect with one another to form "fracture band". The research acquires the key points for prevention in mining the isolated coal pillar with filling method and provides guidelines to implement this technique and to prevent rock burst.

\section{Introduction}

Mining an isolated coal pillar left due to striping mining or unreasonable mining layout with filling method is an inevitable choice for resource-exhausted mining areas [1-3]. With complicated structure of overlying strata on isolated coal pillar, mining coal seam can probably induce the change of the spatial structure and occurrence of rock burst [4-8]. Equivalent mining height is the key index for controlling movement of overlying strata in filling mining working face, so studying equivalent mining height has become a key factor to complete mining of isolated coal pillar successfully. Miao and Jixiong [9] defined equivalent mining height in the first place and proposed an approach to calculate equivalent mining height with gangue-filled in. Zhang et al. [10], in accordance with characteristic differences of controlling different layers of overlying strata, defined critical filling rate and created theorem with regard to filling rate. Jixiong et al. [11] tested roof movement and characteristics of transform for strip coal pillar that is replaced by gangue, and implemented the project of gangue-filled band laid in the middle of stripe coal pillar. Kaijun et al. [12] studied similar simulation using filling method to mine thinner coal seam by super-high water material. They found that, compared to caving method, the degree of activity for overlying strata behind the goaf alleviates, and no carving zone or fracture band occurred. Junfei et al. [13] proposed the method of possibility index diagnosis to judge the possibilities of global 
burst failure and mining for isolated coal mass. Guangwei [14] has presented the test method to study the degree of activity of goaf after mining left stripe coal pillar by pastefilling method, indicating that the intensity of filling material is the main factor to affect subsiding and activating of ground surface. Jiang and $\mathrm{Xu}$, and Zhijie et al. $[15,16]$ employed similar material simulation to study the characteristics of bed separation development and crack distribution under high-located hard-thick strata, and to analyze the development rules and disaster-causing mechanism of hard-thick rock mass in different strata. Atsushi and Hani [17] focused on the principle of instability for an isolated coal pillar, caused by time-dependent skin, degradation, and strength heterogeneity. Linming et al. [18] adopted computed tomography technique to predict potential burst area and degree of danger. Shaojie et al. [19] studied spatial structure and movement rules of overlying strata by using paste-filling to mine strip coal pillar. They showed that as the area mined in coal pillar increases, the structure of overlying strata will transform from "C-type" into "hinge joint" with unequal-height support. Sitao et al. [20] analyzed the mechanism of overall-instability-induced rock burst for isolated coal pillar and proposed the assessment method for burst disaster based on actual bearing capacity. Weijian and Weijun [21] studied the movement mechanism and characteristics of strata induced by coal pillar under three circumstances exchanged by gangue backfill, and they proposed that the movement of quadratic stability is induced by multiple compression from support made of gangue filling and weight-bearing strata. Xikui et al. [22] studied characteristics of structure change of overlying strata in mining strip coal pillar and presented computing method for filling rate based on the control of surface subsidence. Xuesheng et al. and Shilin et al. [23, 24] studied the failure law of coal-rock combination by mechanical experiment and established the damage constitutive model of coal. In $[25,26]$, the researchers optimized the design of roof cutting parameters of gob-side entry in deep coal mine by means of numerical simulation and mechanical modeling of discrete element program.

As for the movement of overlying strata in mining an isolated coal pillar, surface subsidence, and stress distribution from support of filling stuff, a great deal of research has been done in the past years [27-31]. However, it is difficult to find a study into the rule of movement and failure of overlying strata on isolated coal pillar with varied equivalent mining height. The basic static load on isolated coal pillar has a big quantity so it is likely to induce dynamic disasters such as burst. If a large scale of movement and failure from overlying strata occur in mining coal pillar, it will cause an incremental dynamic load on working face. The equivalent mining height has a direct relationship with the maximum height to which the roof of isolated working face subsides and has a considerable significance for mining the isolated coal pillar safely and efficiently.

This paper introduces self-designed layered-mining system and monitoring system for movement of overlying strata. The similar simulation method is employed to analyze evolution rules of displacement field and stress field and the process of progressive failure in overlying strata. The study reveals the rules of transform for overlying strata and mechanism of load releasing and obtains evolution rules for the fracture of overlying strata and fractured arch in adjacent goaf. The findings provide guides for the mining of isolated coal pillar and the design of filling method.

\section{Project Background}

This research is based on C8301 working face with filling method in Yunhe coal mine, Shandong Province, China. Yunhe coal mine is located in Jibei coal field, outcropping in the north of Tangkou exploration area in the city of Jining in Shandong Province. Because a large amount of coal is under surface buildings, strip mining method was employed in the earlier stage. The number of isolated coal pillars in mining areas \#5 and \#8 reaches up to 14 . To collect those left resources safely and to maintain sustainable development of coal mine, Yunhe coal mine carries out a systematic research of filling stuff to replace isolated coal pillar. Equivalent mining height is equal to the mining height of working face minus the height of compacted filling stuff in goaf. For simplification, the mining height of coal seam is seen as equivalent mining depth in experiment.

Working face C8301 is the first filling isolated working face. It is located in the south of mining area \#8 with mining depth of $778 \mathrm{~m}$ and $3.2 \mathrm{~m}$-thick coal seam. The dip angle of coal seam is $7^{\circ}-19^{\circ}$, immediate roof is siltstone with the height of $1.5-2.5 \mathrm{~m}$, and the main roof is gritstone with the height of $6.9-8.4 \mathrm{~m}$. It is $20.1 \mathrm{~m}$ above coal seam where medium sandstone is $25.2 \mathrm{~m}$ high. The structure of coal seam is simple, and the mining method employs the technique of fully mechanized long-slide wall backward mining. The surrounding conditions are as follows: the east side is the goaf out of working face 8308 , the south side is the protective coal pillar for T5-4 fault, the west side is the goaf out of working face 8307, and the north side is the protective coal pillar for roadway in east wing of $-725 \mathrm{~m}$. The width of the working face is $96 \mathrm{~m}$, and the mined area has a length of $424 \mathrm{~m}$. The location of working face C8301 is given in Figure 1.

The filling goaf directly affects the range and strength of movement and failure of overlying strata. The final height after compression of filling stuff determines the spatial structural change of overlying strata and distribution of support pressure on working face, which plays an important role in safe mining. This paper adopted the similar simulation method to study movement and stress distribution of overlying strata on isolated coal pillar based on equivalent mining height.

\section{Process of Model Test}

3.1. Device of Model Test. Because the physical similar simulation method has the advantages of reliability and intuition, it can be used to study movement rules and spatial structure of inclined overlying strata on isolated working face with varied mining height. 


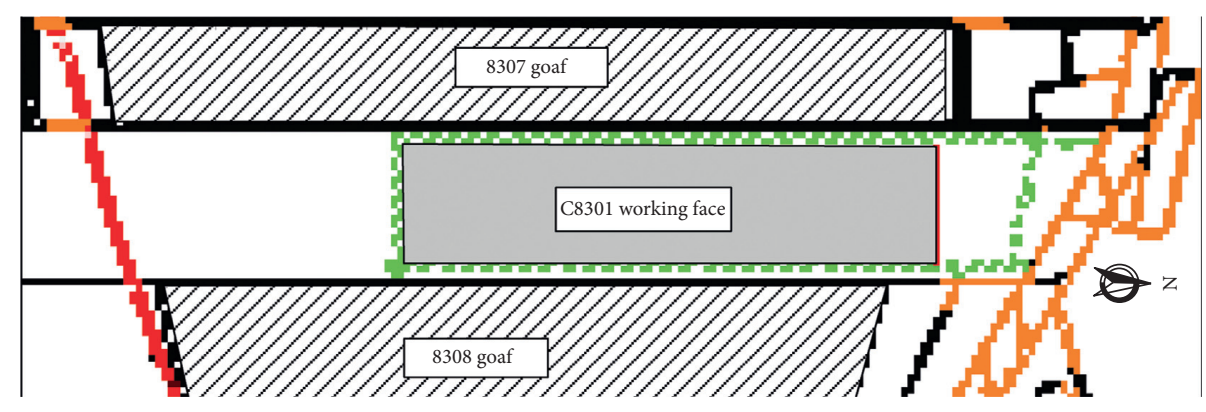

Figure 1: Location map of working face C8301.

On the basis of engineering background and model characteristic, this test utilizes self-developed steel-frame test stand, which is constructed by vertical pillar, baffle, and base floor, as in Figure 2. The test stand has a size of $330 \mathrm{~cm}$ $* 30 \mathrm{~cm}^{*} 140 \mathrm{~cm}$ based on plane strain. On two sides of frame, there are vertical pillars made of two high-intensity carbon-type $U$-bars, which impose lateral restraints on the frame. The floor of the model is connected with its base through blot and vertical pillar to bear the weight of model and trial materials, constructing the plain-strain condition of mining the isolated coal pillar. Paved baffles are fixed on vertical pillars one by one through bolt as the height of trial material increases.

3.2. Model Parameters and Test Scheme. Based on the geological conditions of working face C8301, the plain-strain model for movement of overlying strata in mining the isolated coal pillar with filling method is built up. The ratio of similitude is a key factor to the test result [32]. Geometrical size, unit weight, intensity, and boundary condition of model, as well as applied load and deformation behavior, are expected to meet three laws of similitude. This model has a geometrical similitude ratio, $C_{l}=1: 150$, a bulk density similitude ratio, $C_{r}=1$ : 1.6 , and a stress similitude ratio, $C_{p}=1: 240$. The model roof is applied with equivalent load of $0.062 \mathrm{MPa}$, and the roof and boundaries of two sides are fixed. In accordance with the theory of similar material simulation [33], sand and gypsum are used as aggregate, lime as binder, and mica powder as laminated material. Considering practical geological data from coal and rock layers in working face, mixed proportions in similar materials can be obtained through repeated allocation and comparison. The model includes 24 layers in total, of which the roof has 21 layers and the bottom has only 2 layers. The modeling parameters determined and mixed material proportions can be seen in Table 1 .

To build the model, at first, 3 bases were put on a flat and stable place, and then bolt was used to connect the bases with floor and vertical pillars. Baffles are placed on both sides of floor. Similar material is paved at each layer and compressed to flat. Mica powder is set in the midst of two layers to indicate layering. Figure 3 shows partial process drawing for model building.

\subsection{Layout of Monitoring Points in Model and Mining} Working Face. The actual size of the model is $285 \mathrm{~cm}$ ${ }^{*} 140 \mathrm{~cm}{ }^{*} 30 \mathrm{~cm}$, and the lengths of working faces 8307,8308 , and C8301 are $50 \mathrm{~cm}, 83 \mathrm{~cm}$, and $80 \mathrm{~cm}$, respectively. After

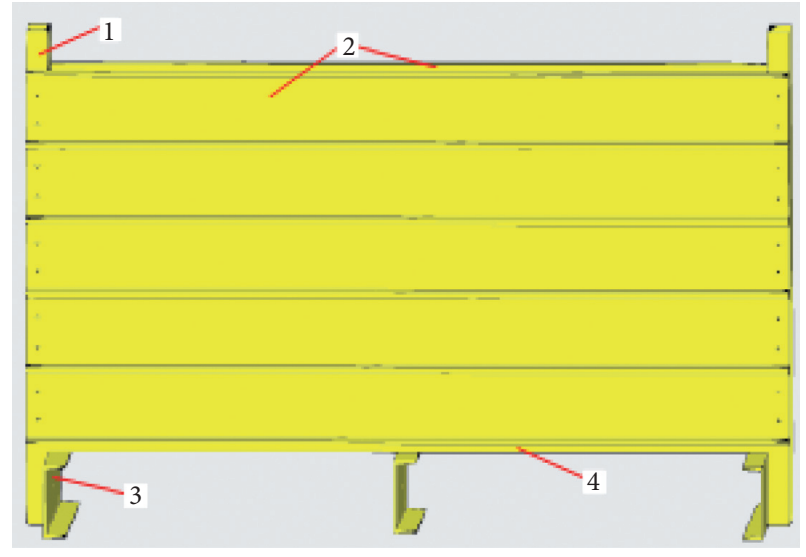

FIGURE 2: Sketch of devices in the model. 1. Vertical pillar. 2. Baffle. 3. Base. 4. Floor.

the model is paved and dried, the surface of model is painted with discrete spots, and noncontact Vic monitoring system for global strain is employed to measure the deformation of surrounding rocks. Vic monitoring system is comprised of high-definition camera and image-analysis software. To study distributing characteristics of stress on working face, 11 sensors are set on the floor of coal seam. The sensor that is set under boundary coal pillar outside working face 8307 is numbered as $1 \#$, and the rest of sensors are numbered as $2 \#$ to $11 \#$ in sequence, of which the sensors set under isolated coal pillar are numbered as $3 \#$ to $8 \#$ in sequence and have an interval of $16 \mathrm{~cm}$ between every two sensors. The sensors $1 \#$ and $11 \#$ are $17 \mathrm{~cm}$ away from the boundary of the model. The spacing distances from $1 \#$ to $3 \#$ are $40 \mathrm{~cm}$ and $30 \mathrm{~cm}$, and the spacing distances from $8 \#$ to $11 \#$ are $25 \mathrm{~cm}, 50 \mathrm{~cm}$, and $26 \mathrm{~cm}$, respectively. The model is described as in Figure 4.

To study the movement mechanism of overlying strata with filling method, filling mining coal, in accordance with the theory of equivalent mining height, is equivalent to mining super-thin coal seam. Because the disturbance caused by repeated mining can cause rock mass to fail, material filled in the model will produce compressive deformation under the function of roof pressure and apply support on the roof, so the roof is likely to collapse in a big scope. This trial test simulates the model with equivalent mining height using filling method and simulates mining process as equivalent mining height increases gradually. Strip mining is adopted in the model in the first place, and caving method is used for mining working faces 
TABLe 1: Parameters of mechanical properties and material ratios.

\begin{tabular}{|c|c|c|c|c|c|c|c|c|c|}
\hline \multirow{2}{*}{$\begin{array}{l}\text { Serial } \\
\text { number }\end{array}$} & \multirow{2}{*}{ Lithology } & \multirow{2}{*}{$\begin{array}{c}\text { Actual } \\
\text { thickness (m) }\end{array}$} & \multirow{2}{*}{$\begin{array}{c}\text { Model } \\
\text { thickness }(\mathrm{cm})\end{array}$} & \multirow{2}{*}{$\begin{array}{c}\text { Compressive } \\
\text { strength }(\mathrm{MPa})\end{array}$} & \multirow{2}{*}{$\begin{array}{c}\text { Simulated } \\
\text { strength }(\mathrm{kPa})\end{array}$} & \multicolumn{4}{|c|}{ Weight of material $(\mathrm{kg})$} \\
\hline & & & & & & Sand & Lime & Gypsum & Water \\
\hline 1 & Gritstone & 33 & 25 & 23.0 & 137.72 & 267.19 & 46.76 & 20.04 & 37.11 \\
\hline 2 & Clay rock & 21 & 16 & 11.0 & 65.87 & 183.21 & 9.16 & 21.38 & 23.75 \\
\hline 3 & Siltstone & 15 & 11 & 14.0 & 83.83 & 110.21 & 18.37 & 18.37 & 16.33 \\
\hline 4 & Fine sandstone & 13 & 10 & 28.0 & 167.66 & 106.88 & 13.36 & 13.36 & 14.84 \\
\hline 5 & Clay-sandstone & 7 & 5 & 13.0 & 77.84 & 57.25 & 2.86 & 6.68 & 7.42 \\
\hline 6 & Fine sandstone & 3 & 2 & 28.0 & 167.66 & 21.38 & 2.67 & 2.67 & 2.97 \\
\hline 7 & Siltstone & 5 & 4 & 16.0 & 95.81 & 40.08 & 6.68 & 6.68 & 5.94 \\
\hline 8 & Medium sandstone & 5 & 4 & 25.0 & 149.70 & 44.53 & 2.67 & 6.23 & 5.94 \\
\hline 9 & Fine sandstone & 3 & 2 & 28.0 & 167.66 & 21.38 & 2.67 & 2.67 & 2.97 \\
\hline 10 & Clay rock & 4 & 3 & 11.0 & 65.87 & 34.35 & 1.72 & 4.01 & 4.45 \\
\hline 11 & Siltstone & 7 & 5 & 16.0 & 95.81 & 50.10 & 8.35 & 8.35 & 7.42 \\
\hline 12 & $\begin{array}{l}\text { Clay and sandstone } \\
\text { interbedded }\end{array}$ & 7 & 5 & 13.0 & 77.84 & 57.25 & 2.86 & 6.68 & 7.42 \\
\hline 13 & Siltstone & 4 & 3 & 16.0 & 95.81 & 30.06 & 5.01 & 5.01 & 4.45 \\
\hline 14 & Medium sandstone & 4 & 3 & 25.0 & 149.70 & 33.40 & 2.00 & 4.68 & 4.45 \\
\hline 15 & Clay rock & 4 & 3 & 11.0 & 65.87 & 34.35 & 1.72 & 4.01 & 4.45 \\
\hline 16 & Gritstone & 7 & 5 & 23.0 & 137.72 & 53.44 & 9.35 & 4.01 & 7.42 \\
\hline 17 & Fine sandstone & 3 & 2 & 28.0 & 167.66 & 21.38 & 2.67 & 2.67 & 2.97 \\
\hline 18 & Medium sandstone & 5 & 4 & 25.0 & 149.70 & 44.53 & 2.67 & 6.23 & 5.94 \\
\hline 19 & Clay-sandstone & 3 & 2 & 13.0 & 77.84 & 22.90 & 1.15 & 2.67 & 2.97 \\
\hline 20 & Gritstone & 5 & 3 & 23.0 & 137.72 & 32.06 & 5.61 & 2.40 & 4.45 \\
\hline 21 & Siltstone & 4 & 3 & 16.0 & 95.81 & 30.06 & 5.01 & 5.01 & 4.45 \\
\hline 22 & Coal & 4 & 4 & 11.1 & 66.41 & 45.80 & 5.34 & 2.29 & 5.94 \\
\hline 23 & Fine sandstone & 5 & 4 & 28.0 & 167.66 & 42.75 & 5.34 & 5.34 & 5.94 \\
\hline 24 & Medium sandstone & 16 & 12 & 25.0 & 149.70 & 133.59 & 8.02 & 18.70 & 17.81 \\
\hline
\end{tabular}

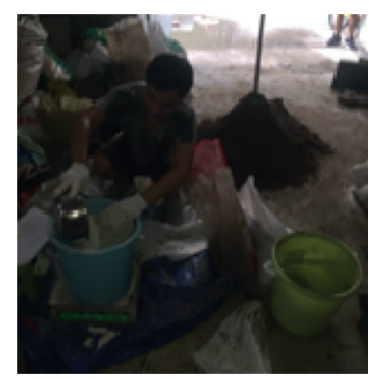

(a)

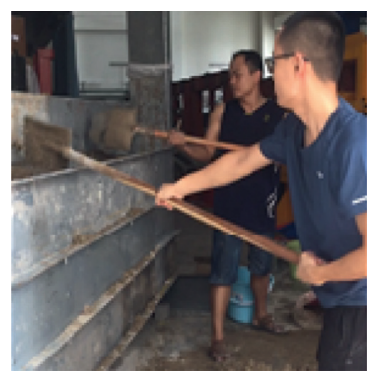

(b)

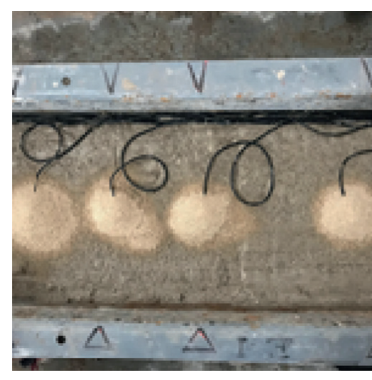

(c)

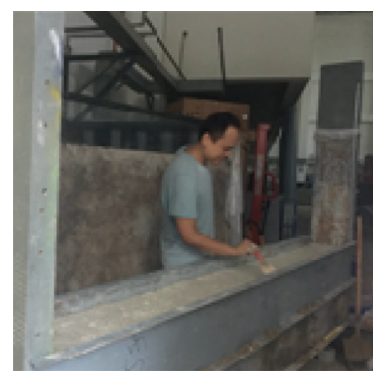

(d)

Figure 3: Process of model building. (a) Material matching. (b) Material filling. (c) Sensor layout. (d) Mica powder paving.

8307 and 8308 . The coal pillar left in the middle is mined as equivalent mining height increases as order. The working face C8301 is made of PVC plate with a size of $300 \mathrm{~mm}^{*} 50 \mathrm{~mm}$, which is $1.3 \mathrm{~mm}$ thick. Representative filling rate before mining is $100 \%$, and it is declining by $5 \%$ as each layer is mined, so as to model the movement rule and stress distribution of overlying strata on coal pillar with equivalent mining height. Filling working face set aside $5 \mathrm{~cm}$ unmined space on two ends to model support effect of section coal pillar to overlying strata.

\section{Analysis of Result}

4.1. Process of Progressive Failure of Overlying Strata. In order to visually study the movement of overlying strata after filling mining, photos were taken in different stages for comparison in modeling. Figure 5 shows the process of progressive failure of overlying strata in filling mining for working face C8301. From the development of fractures in overlying strata of working faces on two sides using caving mining, it denotes that caving mining can lead to vertical fracture and bed separation in overlying strata. After mining, vertical fractures are produced in walls on two sides of goaf and propagate upwards, cutting through bed separation at a certain level to form fracture arch. The fracture arch in overlying strata on goaf 8307 has a semicircle shape, and the height is $19.2 \mathrm{~m}$. The goaf 8308 has a trapezoidal fracture arch with a height of $54.5 \mathrm{~m}$. The strata inside fracture arch form the structure of failure and rotation. The roof of fracture arch has a fully developed fracture, and non-passthrough vertical fractures in strata above fracture arch are developing. The overlying strata include caving zone, fracture zone, and bending-subsidence zone. 


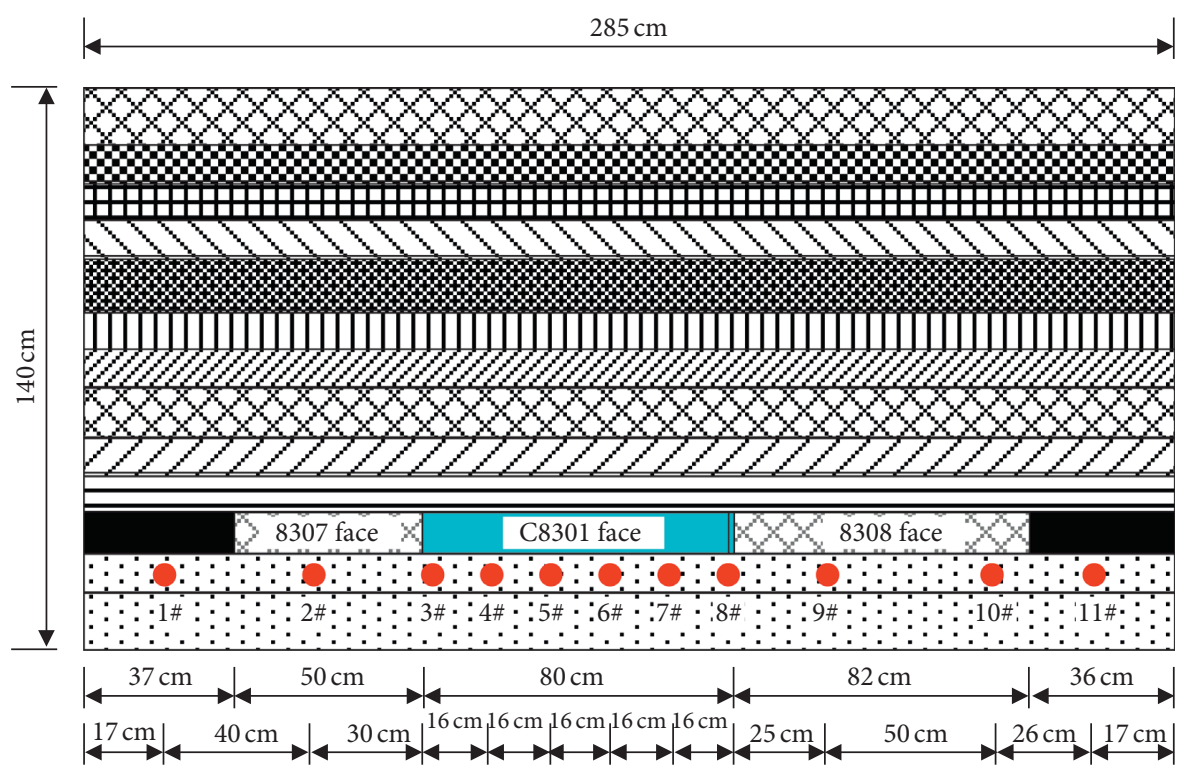

(a)

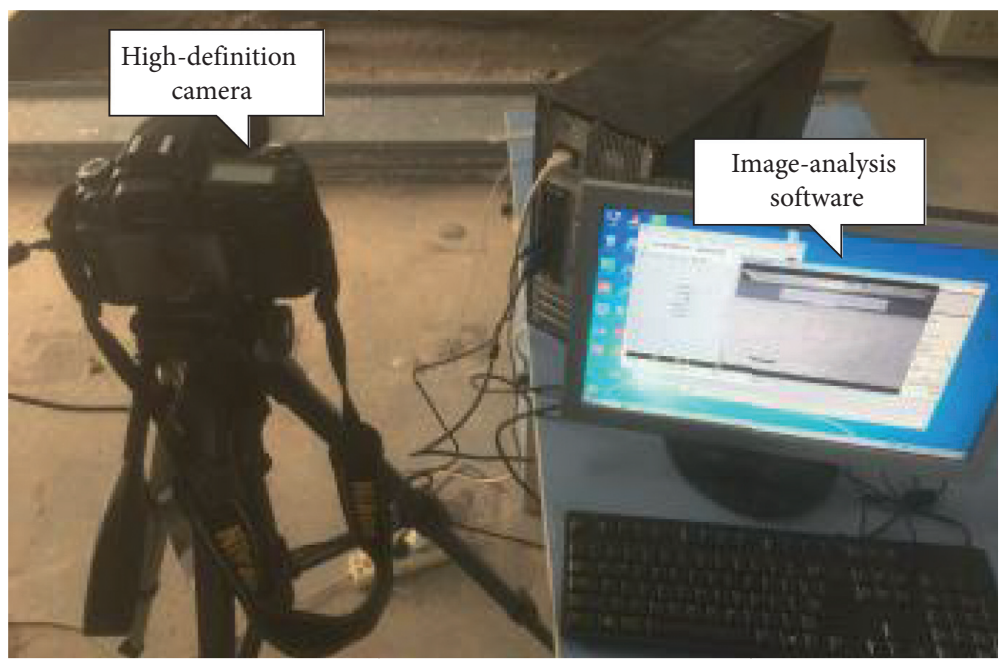

(b)

FIgURE 4: Monitoring system for strain of physical model. (a) Schematic diagram of physical model. (b) Noncontact monitoring system of Vic-2D for global strain.

When the equivalent mining height is less than $0.4 \mathrm{~m}$, the immediate roof of the filling goaf has a slight bending and subsidence and is developing bed separation fracture in a small range. The roof of the center part in the goaf has been damaged to some extent, but no failure occurs. Therefore, the roof still has a good integrality. When equivalent mining height increases to $0.8 \mathrm{~m}$, the immediate roof of filling goaf will bend and subside, and the fractures of bed separation in the center of the goaf have increased the height, but vertical fracture is not produced. When the equivalent mining height reaches $1.2 \mathrm{~m}$, the immediate roof on the edge of the goaf produces vertical fracture for the first time. When the equivalent mining reaches $1.4 \mathrm{~m}$, the vertical fracture continues to propagate upward until the area under thick-hard rock layer. The lower parts of the immediate roof and basic roof break up. Meanwhile, the bed separation occurs between thick-hard rock layer and rock layers below. When the equivalent mining height rises up to $1.8 \mathrm{~m}$, the height of the bed separation under thick-hard rock layer propagates further. Plastic failure takes place in section coal pillars between goaf 8301 and goaf 8308 . The existing bed separation in goaf 8308 will shut to some extent. When the equivalent mining height is $2 \mathrm{~m}$, the height of the bed separation under thick-hard rock reaches its maximum value, and a large range of fractures are produced at $30 \mathrm{~m}-40 \mathrm{~m}$ height above the middle part of goafs 8301 and 8307 with a length of $70 \mathrm{~m}$. When the equivalent mining height increases to $2.2 \mathrm{~m}$, plastic failure takes place in section coal pillar between goaf 8301 and goaf 8308 . On the right side of goaf 8308, vertical fractures cut through one another and propagate to the top of the model, getting through vertical fracture on the left side of goaf C8301. Overlying 


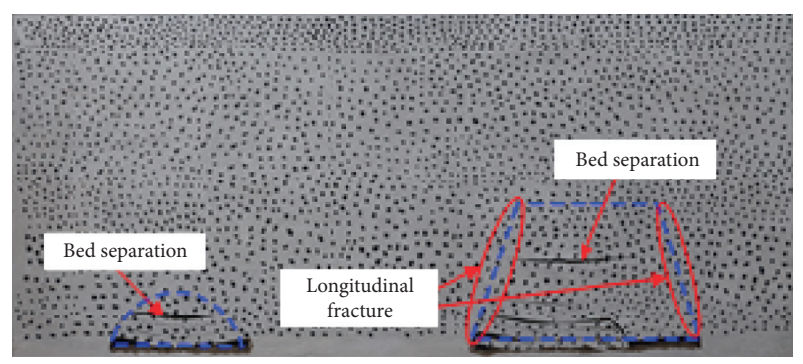

(a)

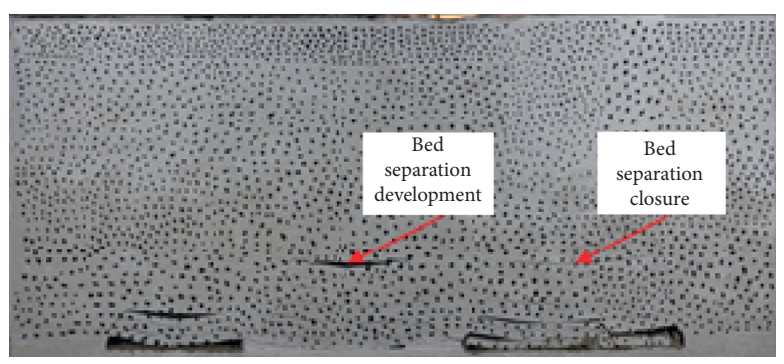

(b)

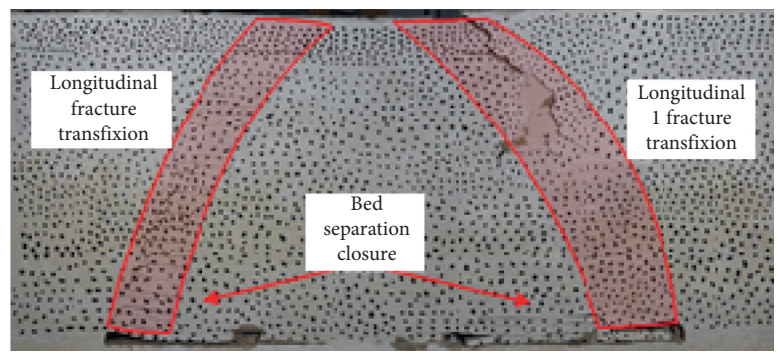

(c)

FIGURE 5: Situation of fracture development before filling mining. (a) Fracture development of overlying strata before mining. (b) Fracture development of overlying strata in mining. (c) Fracture development of overlying strata after mining.

strata on goaf C8301 and goaf 8308 will subside as global. Vertical fractures on the left side of goaf propagate upward but do not arrive at the top of the model. When the equivalent mining height increases to $2.6 \mathrm{~m}$, the section coal pillar between goaf C8301 and 8307 will have plastic failure, and the existing bed separation in overlying strata will shut slightly. The fractures of bed separation thus reclose. Vertical fractures on the left side of goaf 8307 intersect with each other and propagate to the top of the model. Meanwhile, on the top of the semicircle fracture arch, a new cut-through vertical fracture parallel to fracture line on the left is created. When the equivalent mining height reaches up to $2.8 \mathrm{~m}$, the area surrounded by the fracture lines on the left side of goaf 8307 and on the right side of goaf 8308 will subside further. Vertical fractures are developing more completely, and the strata in the fracture arch in goaf 8307 have dislocated. As the equivalent mining height increases further, overlying strata surrounded by fractures of 8307 and 8308 will subside far significantly, and all the existing bed separations in three goafs will close.

4.2. Analysis of Deformation of Overlying Strata. As the equivalent mining height increases, the movement of overlying strata presents a remarkable staged evolution feature. We used Vic-2D monitoring system of noncontact global strain to identify dispersive spots sprayed on the model surface. The contour of vertical displacement is plotted in Figure 6.

From Figure 6 it can be seen that, with mining height increasing from $0.2 \mathrm{~m}$ to $0.8 \mathrm{~m}$, no obvious bed separation and vertical fractures are produced in goaf C8301. The strata of the roof are bending and subsiding as global. The width of the immediate roof expands from 33.7 to $60 \mathrm{~m}$, and the height propagates from 15.9 to $68.4 \mathrm{~m}$. The overlying strata remain as global continuum and would not produce caving zone and fracture band. Accordingly, it is shown that the equivalent mining height and the width of working face have affected overlying strata on the goaf, but there is still some space for global subsidence of overlying strata. The subsidence of overlying strata in goaf C8301 has the smallest quantity, and the overlying strata on the two sides of the caving goaf still remain stable.

When the equivalent mining height increases from $0.8 \mathrm{~m}$ to $2.4 \mathrm{~m}$, the movement intensity and the scale of overlying strata are continuously increasing and interact with the overlying strata on the goaf. This includes the following: (1) the range of movement of strata expands continuously, and the height of roof bending and subsiding in goaf C8301 in vertical direction reaches the top of the model. At horizontal direction, the range of roof bending and subsiding in goaf C8301 connects with the overlying strata of goaf 8308. (2) It is at $29 \mathrm{~m}$ above the goaf that a $43.7 \mathrm{~m}$ long bed separation is developing and reaches the maximum width of $2.1 \mathrm{~m}$. The strata beneath bed separation break down at the same pace for each layer, and the strata near goaf 8307 and goaf 8308 have facture angles of $69^{\circ}$ and $64^{\circ}$, respectively. In the middle of suspending strata is a vertical non-cut-through fracture. (3) The section coal pillar between goaf C8301 and goaf 8308 subsides, and the bed separation over goaf 8308 is closing. The displacements of strata near coal pillar on lateral side of goaf 8307 remain unchanged. As the equivalent mining height increases, the same paces of movement for each layer of overlying strata are distorted as vertical displacements in each layer have great differences. Accordingly, it is shown that the bed separation in the goaf cuts off the path passing down load from overlying strata, causing the load borne on strata beneath bed separation to be passed onto section coal 


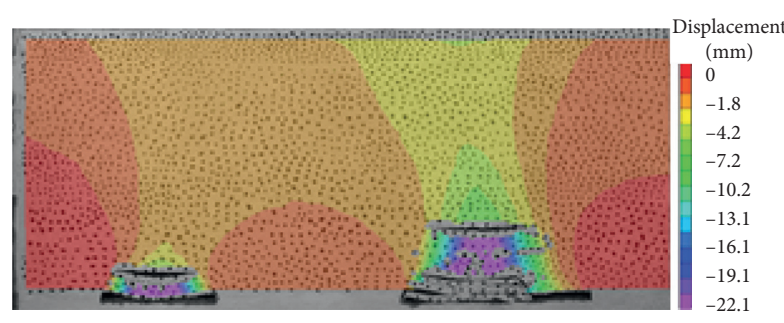

(a)

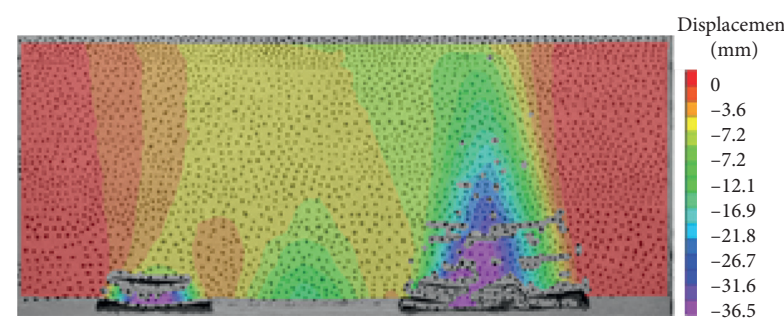

(c)

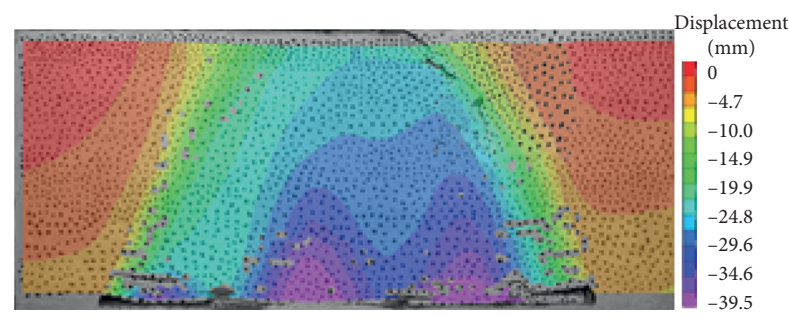

(e)

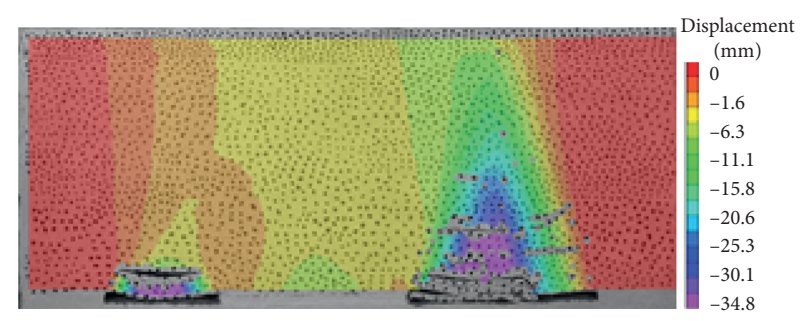

(b)

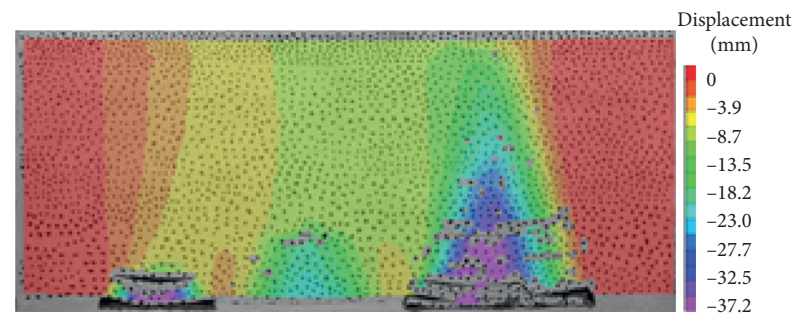

(d)

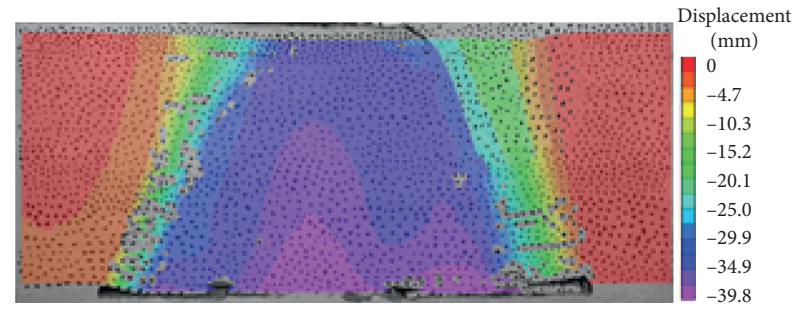

(f)

FIGURE 6: Displacement contour of overlying strata on coal pillar with varied equivalent mining height (mm). (a) Isolated coal pillar before mining. (b) Displacement of overlying strata with equivalent mining height of $0.8 \mathrm{~m}$. (c) Displacement of overlying strata with equivalent mining height of $1.6 \mathrm{~m}$. (d) Displacement of overlying strata with equivalent mining height of $2.4 \mathrm{~m}$. (e) Displacement of overlying strata with equivalent mining height of $3.2 \mathrm{~m}$. (f) Displacement of overlying strata with equivalent mining height of $4.0 \mathrm{~m}$.

pillar and result in plastic failure inside the section coal pillar in the first place because of a great quantity of loading near 8308 goaf. The jointed rock beam on the left side of goaf 8308 rotates back slightly.

As the equivalent mining height increases further, the roof of goaf C8301 subsides down more obviously. This indicates that the original bed separation starts to close. The vertical fractures cut through and propagate upward, so the range of strata bending and subsiding continues to expand. When equivalent mining height reaches $2.6 \mathrm{~m}$, the section coal pillar between goaf C8301 and goaf 8308 collapses, and the strata lacking in support subsides obviously. The fracture line of strata on the right side of goaf 8308 is a $30^{\circ} \mathrm{m}$ wide 'fracture band' that extends upward from edge to the roof of the model. Two high-level roofs in goaf interconnect horizontally, and the roof at $105.3 \mathrm{~m}$ above coal seam subsides by $2.5 \mathrm{~m}$. Meanwhile, the section coal pillar between goaf C8301 and goaf 8307 produces failure with roof subsiding by $2^{\circ} \mathrm{m}$ as global. When mining coal seam is finished, the fracture line of strata on the left side of goaf 8307 is a $28^{\circ} \mathrm{m}$ wide "fracture band" that extends upward from edge to the roof of the model.

The vertical displacement of the roof on filling working face increases with the increase in the equivalent mining height. With a small equivalent mining height, the roof of filling goaf only has bending deflection as global, and its structure does not have essential failure, but only forms fracture band and bending-subsiding band. As the equivalent mining height gradually increases, the bending deflection of rock beam in roof also increases and reaches up to extreme deflection. The lower roofs produce bed separation, fracture, and caving in sequence. The degree and range of failure increase significantly and induce second movement of overlying strata on two adjacent caving goafs, in which the section coal pillar with a larger width is the first to fail. The length of the bulk failing in roof of goaf is a big quantity.

4.3. Analysis of Displacement of Overlying Strata. According to monitoring data of overlying strata from Vic$2 \mathrm{D}$ system on isolated coal pillar in the process of mining, vertical displacement of different layers over coal seam is derived as in Figure 7. In this paper, EMH in the figures represents equivalent mining height. It can be seen from Figure 7 that as the equivalent mining height increases, isolated coal pillar shows features as follows:

(1) In the process of coal pillar mining, the stability of the section coal pillar is a significant factor that influences the roof at lower level. See the instance of the roof at $20 \mathrm{~m}$ above coal seam; the plot of 


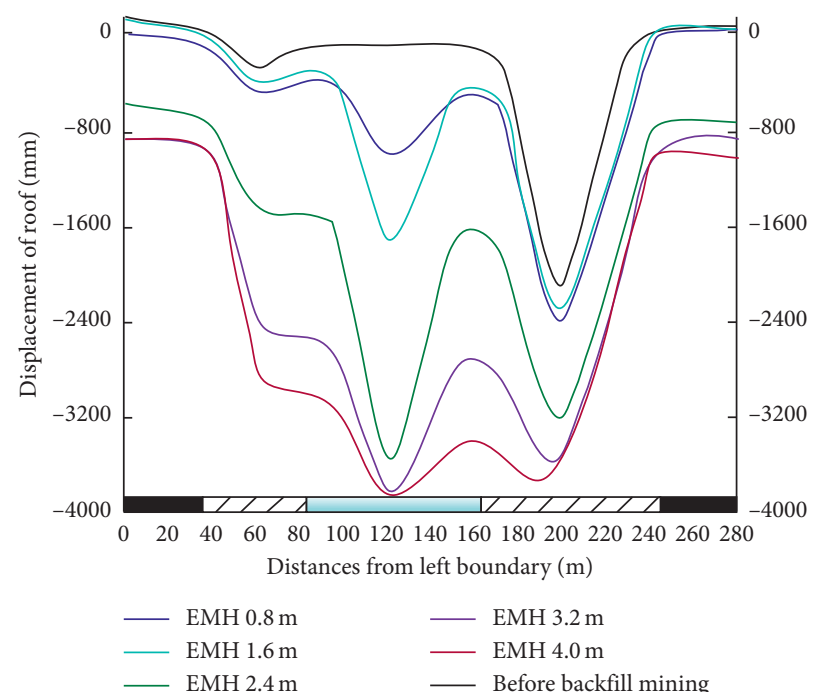

(a)

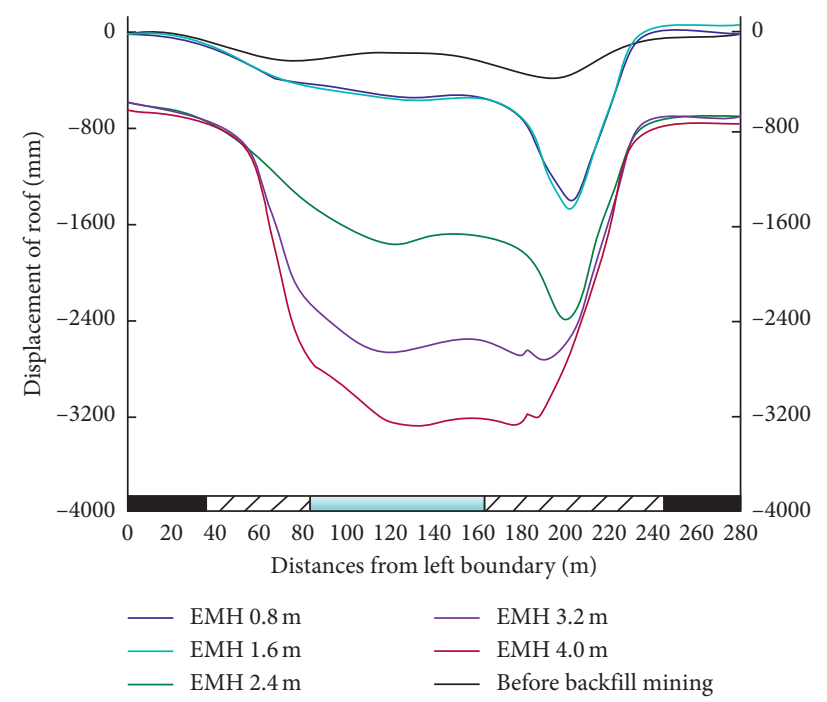

(c)

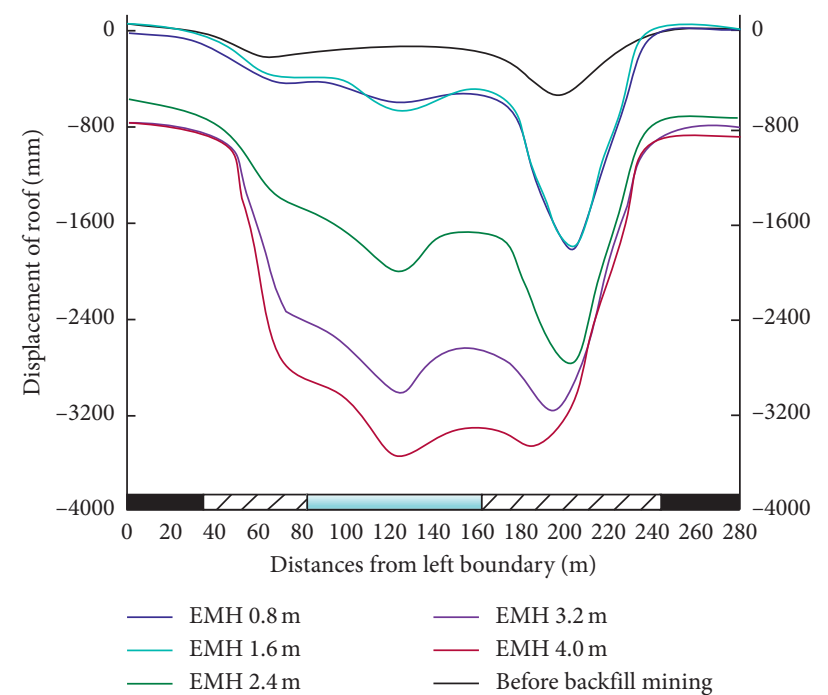

(b)

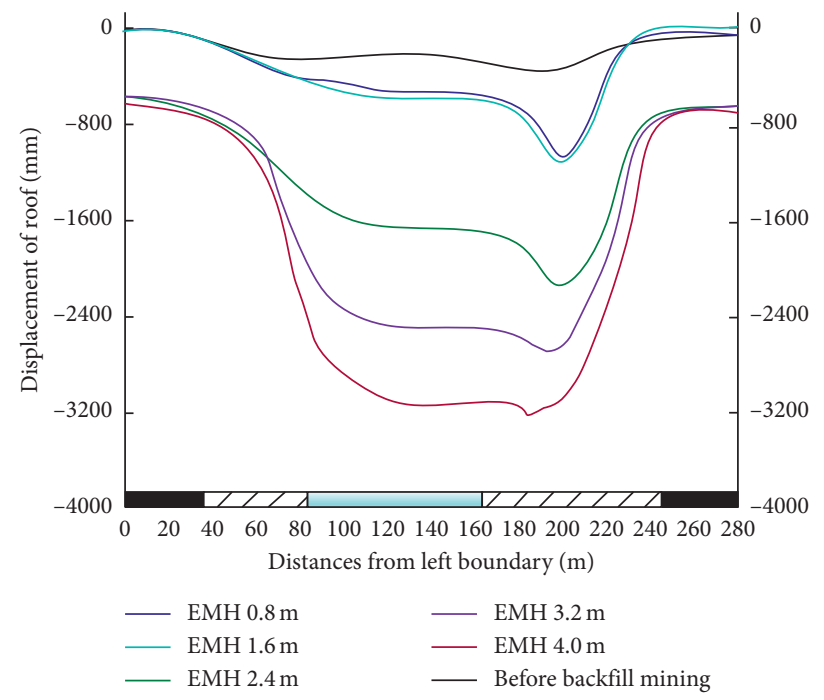

(d)

Figure 7: Vertical displacement of overlying strata after mining. (a) Plot of roof subsiding at $20 \mathrm{~m}$ above coal seam. (b) Plot of roof subsiding at $40 \mathrm{~m}$ above coal seam. (c) Plot of roof subsiding at $60 \mathrm{~m}$ above coal seam. (d) Plot of roof subsiding at $80 \mathrm{~m}$ above coal seam.

overlying strata subsiding distributed as bimodal and turning point in trough appears on section coal pillar between isolated working face and adjacent large caving goaf as in Figure 7(a).

(2) As the equivalent mining height increases, overlying strata continue to subside, which indicates that the equivalent mining height provides strata movement with space. In sum, lower strata have the largest subsiding displacement and as the level of strata rises, the subsiding displacements of overlying strata gradually decline and tend to be stable. The whole plot of overlying strata subsiding has a basin shape, and the edges on the two sides of the model have the least subsidence, $536 \mathrm{~mm}$. The most subsidence of strata occurs in the middle of the area between the midst of isolated coal pillar and adjacent large goaf.

(3) The subsidence of overlying strata has a nonlinear relation with the equivalent mining height. When the equivalent mining height is less than $1.6 \mathrm{~m}$, the subsidence of overlying strata has the least value. Most of all, the roof at $40 \mathrm{~m}$ height over coal seam and strata above have the same plots of subsiding movement. When the equivalent mining height is greater than $1.6 \mathrm{~m}$, mining activity can cause prominent subsidence of overlying strata, which indicates that, with a small equivalent mining height, the extent of roof subsiding is restricted. The roofs at a lower level will fail and form bed separations. 
Upper roofs only take the movements of subsiding as global. As equivalent mining height increases further, the degree of overlying strata subsiding expands remarkably.

(4) With equivalent mining height rising, overlying strata on isolated working face and goafs on two sides interact with each other. Mining isolated working face will induce the second subsidence of overlying strata of goafs on two sides, of which overlying strata over large caving goaf have a remarkable subsidence. When the equivalent mining height reaches up to a certain level, the middle part of overlying strata on isolated working face has more subsidence than that on large caving goafs.

4.4. Analysis of Stress Monitoring. Coal seam mining induces movement of overlying strata and mechanism change of stress transferring. The spatial structure of overlying strata shows the characteristics of staged evaluation as equivalent mining height increases. By studying stress change around goaf to acquire current situations of surrounding rocks at different places, deformation and failure type of surrounding rocks can be judged. Based on these, the schemes of mining design can be optimized to prevent dynamic disasters caused by spatial structure failure of overlying strata. Stress sensor setup at the bottom of coal seam recorded changing process of incremental value of vertical stress. Stress sensor 9\# recorded some unusual states and data loss, so it can be presumed that stress sensor 9 \# has broken down. The data from the rest of the stress sensors is changing with the equivalent mining height as shown in Figure 8.

It can be seen from Figure 8 that using caving method to mine working faces on two sides can cause change of spatial structure, causing loads to transfer from overlying strata to isolated coal pillar. This can be illustrated in the plot with the data of stress sensors from $3 \#$ to 8 \# rising and the average incremental stress being $83 \mathrm{kPa}$. Stress sensors $2 \#$ and 10\# below goafs on two sides show a decline trend, of which incremental stress is $-96 \mathrm{kPa}$ and $-69 \mathrm{kPa}$. In isolated coal pillar mining, as the equivalent mining height increases, the supporting stress in the center of the coal pillar drops down and the supporting stress around the section coal pillar increases gradually. In particular, stress sensor $8 \#$ is below section coal pillar on side of goaf 8308 , and its increment stress has a significant rise. This is because the equivalent mining height provides space for roof of isolated working face to subside. The differences of thickness and intensity between roof strata cause nonuniform movement at different levels of strata. Thus, it indirectly helps create conditions in which bed separation can be produced, developed, and cut through, and loading from overlying strata can be transferred to section coal pillar on isolated working face by suspended rock beam. The overlying strata on section coal pillar form unsymmetrical T-shape structure for stress transfer [5, 34]. Because goaf 8308 has a larger width, overlying strata

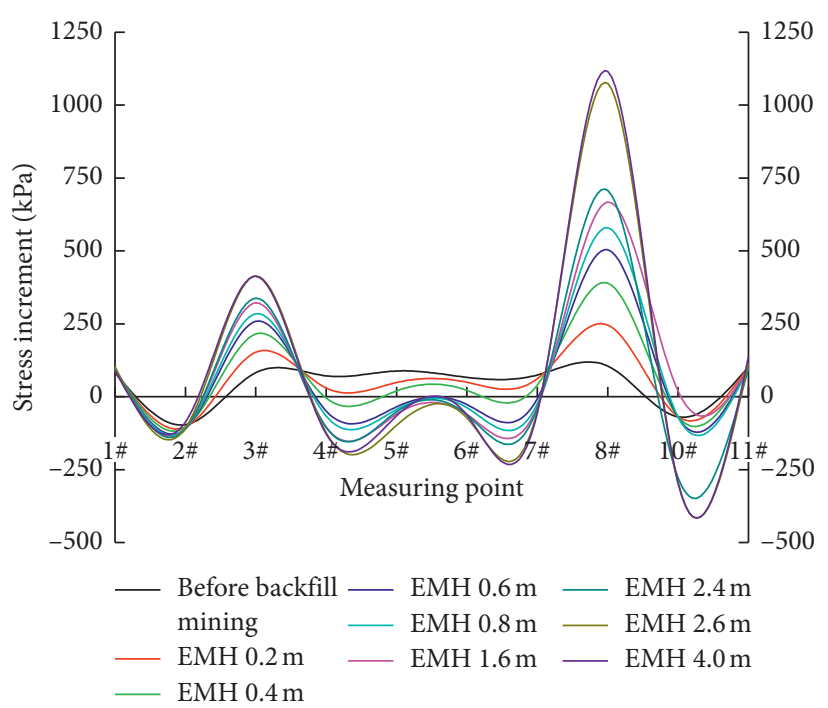

FIgURE 8: Plot of incremental stress changing on the bottom of coal seam with varied equivalent mining height.

transfer more loads to section coal pillar and promotes stress increasing sharply on stress sensor 8\#.

With the equivalent mining height increasing, the stress in mining the isolated coal pillar is distributed as $\mathrm{W}$-shape. This is because the equivalent mining height has a small initial value and the roof of isolated working face has a major movement of bending and subsidence. Meanwhile, bed separation in roof cuts off the path of stress transfer and results in progressive reduction of incremental stress on working face. On the other hand, as the equivalent mining height increases continuously, the original bed separation in roof starts to close. The roof in the middle of isolated working face moves completely, thus leading to a stable trend of incremental stress in this area.

While the equivalent mining height increases from $2.4 \mathrm{~m}$ to $2.6 \mathrm{~m}$, incremental stress for section coal pillar tends to jump. Stress sensors $3 \#$ and $8 \#$ have varying values of $338-414 \mathrm{kPa}$ and $707-105 \mathrm{kPa}$, respectively, with amplifications of $22.5 \%$ and $52.5 \%$. As the equivalent mining height continue to increase, the stress on the bottom rock has a slight increment and the numerical plot recorded by sensors remains constant. This is because the height of fractures in roof increases steadily to create a big quantity of loading on coal pillar. If the equivalent mining height reaches $2.6 \mathrm{~m}$, the section coal pillar will be able to cause deformation under overburdened stress more than critical value. It is likely to induce cut-through of roof fractures between isolated working face and goafs on two sides. Thus, it provides more space for subsidence of overlying strata and makes vertical fractures develop faster and interconnect on the top of the model. The balanced structures are created in overlying strata of three goafs.

\section{Evolution Characteristics of Overlying Strata on Filling Isolated Working Face}

Before mining the isolated working face, the structures of overlying strata of goafs on two sides are in a relative stable state. The overlying strata on caving goaf have a wide range 
of subsidence and a highly developed bed separation. The isolated coal pillar bears, as base, dead load of overlying strata and weight of suspended rock layer on goafs on two sides. While isolated coal pillar is mined using filling method, overlying strata of filling goaf move slowly and bed separation has a slight development. There is a transitional area between filling goaf and caving goaf, in which the movement intensity of overlying strata and the height of bed separation are in the medium level. As the equivalent mining height increases gradually, the roof of filling goaf subsides and even breaks up, so it can cause failure of temporary stable structure of goafs on two sides and second movement of higher-level overlying strata. The equivalent mining height directly influences the characteristics of the spatial structure of overlying strata on filling working face and has a considerable significance for the evolution of inclined spatial structure of overlying strata in three working faces.

\subsection{Movement Rule of Overlying Strata on Isolated Coal Pillar} by Equivalent Mining Height. With the equivalent mining height increasing, the spatial structure of overlying strata on filling goaf and caving goafs on two sides is changing in sequence. The main process is as follows: (1) Compact filling goaf corresponds to a small equivalent mining height. There is a limited space for roof in filling goaf to subside, of which the immediate roof is going to bend and subside. The overall structure of overlying strata remains complete. (2) As the equivalent mining height increases, the space for the roof of filling goaf to subside expands correspondingly. When the equivalent mining height is greater than the maximum deflection of immediate roof of filling goaf, the immediate roof will break up and the basic roof will bend and subside. (3) As the equivalent mining height increases continuously, the range and degree of overlying strata on filling goaf expand further. If the equivalent mining height is greater than the maximum deflection of the basic roof, the basic roof breaks up and the caving goaf on two sides remains stable. (4) When the equivalent mining height reaches a certain level, fractures in filling goaf keep developing and cut through the original fractures in adjacent small goaf in horizontal direction. The middle part between two goafs starts to be activated. (5) With the equivalent mining height increasing further, overlying strata on filling goaf also cut through the adjacent large goaf in horizontal direction. Three goafs interact with each other in a large scale, which has the same theory as evolution rules of structure of overlying strata in mining the isolated coal pillar using caving method.

To summarize the whole process of trial test, the equivalent mining height determines the extreme space for roof to subside and results in staged differences for evaluation of the immediate roof, basic roof, and overlying strata on adjacent goafs. The equivalent mining height that causes roof of isolated working face and goaf on two sides to be instable is defined as critical equivalent mining height as in Table 2 .
5.2. Functional Mechanism of Spatial Structure Evolution of Equivalent Mining Height. The equivalent mining height has an influence on the structure of overlying strata of isolated working face as in Figure 9. It can be seen that $W, W 1$, and $W_{2}$ are widths of isolated coal pillar, adjacent small caving goaf, and adjacent large caving goaf, respectively; $h_{1}$ and $h_{2}$ are the height of strata in carving zone and the height of strata in bed separation zone in mining the isolated coal pillar using filling method. $h_{3}$ is the height of strata in bed separation zone using caving method. Before mining the isolated working face, upper strata have a complete structure and overlying strata on goafs at two sides are in a relatively stable state. The isolated working face bears dead load and load transferred from goafs on two sides. As the equivalent mining height reduces, the roof of isolated working face will bend, break, and rotate and the load on overlying strata is transferred to section coal pillar. Section coal pillar under high pressure will produce plastic failure to reduce the ability of support. The arch-like structure in goafs on two sides will lose support from the roof of arch, and the fractures in isolated working face can intersect with horizontal fractures in goafs on two sides, producing new cracks and bed separation. The roofs of three goafs start to move mutually.

When the equivalent mining height is small, the roof will bend and subside slightly as global and fractures will not be produced in it. That is, if $h_{1}$ is approximated to zero, bed separation is produced slowly in the middle roof of goaf. Upper strata transfer loads to the edge of bed separation, and stress concentration starts to appear around section coal pillar, but the structure of overlying structure still remains stable. When the equivalent mining height increases gradually, lower roofs on isolated working face start to fracture and rotate for each layer, which means that the height of strata in caving zone $\left(h_{1}\right)$ starts to increase and the height of roof in bed separation $\left(h_{2}\right)$ would then increase. Overlying strata transfer more loads to the edge of bed separation zone, leading to a higher stress concentration. If the loading on section coal pillar is beyond the extreme intensity of the coal pillar, the section coal pillar will induce plastic failure and cause upper roof to subside, and then the height of bed separation zone goes up further. As the equivalent mining height continues to increase, the range of overlying strata producing bed separation on isolated coal pillar will increase. Adjacent large goaf has high overlying strata, so it can transfer more loads to isolated coal pillar, which leads to a higher stress concentration. It can be shown that when the equivalent mining height increases to a certain level, the section coal pillar near large caving goaf will fail in the first place.

\section{Conclusions}

This paper has studied the failure process of overlying strata and the changing rules of stress in isolated working face C8301 in a filling mining model in Yunhe coal mine designed by self-developed similar simulation system. It also analyzes the influences of equivalent mining height on 
TABle 2: Definitions for varied critical mining height.

\begin{tabular}{|c|c|c|c|c|c|}
\hline $\begin{array}{l}\text { Immediate roof on } \\
\text { filling goaf }\end{array}$ & $\begin{array}{l}\text { Basic roof on } \\
\text { filling goaf }\end{array}$ & $\begin{array}{l}\text { Adjacent large } \\
\text { caving goaf }\end{array}$ & $\begin{array}{l}\text { Adjacent small } \\
\text { caving goaf }\end{array}$ & $\begin{array}{c}\text { Equivalent } \\
\text { mining height }\end{array}$ & Description for critical mining height \\
\hline Breaks up & Breaks up & Instable & Instable & $h_{e}>h_{e 4}$ & $\begin{array}{l}h_{e l}: \text { critical equivalent mining height for } \\
\text { immediate roof breaking up in filling goaf }\end{array}$ \\
\hline Breaks up & Breaks up & Instable & Stable & $h_{e 3}<h_{e} \leq h_{e 4}$ & $\begin{array}{l}h_{e 2}: \text { critical equivalent mining height for } \\
\text { basic roof breaking up in filling goaf }\end{array}$ \\
\hline Breaks u & up & St & Stable & $h_{e 2}<h_{e} \leq h_{e 3}$ & $\begin{array}{l}h_{e 3} \text { :critical equivalent mining height for } \\
\text { adjacent large caving goaf in instability }\end{array}$ \\
\hline Breaks up & $\begin{array}{l}\text { Bends and } \\
\text { subsides }\end{array}$ & Stable & Stable & $h_{e 1}<h_{e} \leq h_{e 2}$ & $\begin{array}{l}h_{e e}: \text { critical equivalent mining height for } \\
\text { adjacent small caving goaf in instability }\end{array}$ \\
\hline Bends and subsides & Complete & Stable & Stable & $0<h_{e} \leq h_{e 1}$ & \\
\hline
\end{tabular}

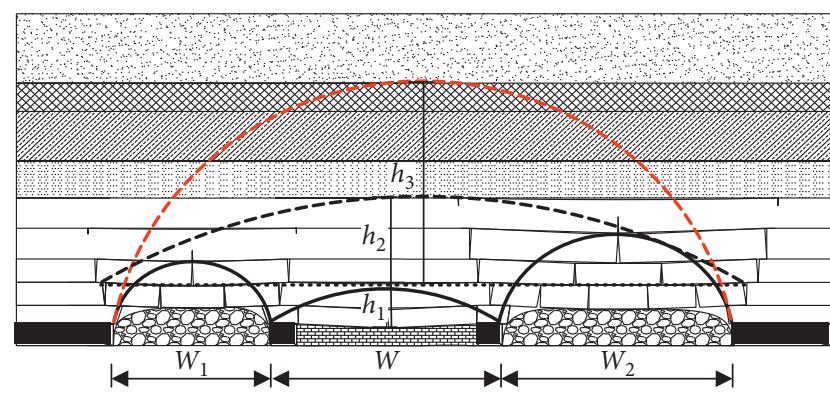

Figure 9: Plot of structure of overlying strata with varied equivalent mining height.

stability of overlying strata. Based on these, the paper has studied the movement rules of overlying strata on goafs by filling mining working face and caving mining on two sides with increasing equivalent mining height. The control of the equivalent mining height and the key areas that need to be reinforced in support are demonstrated in filling mining of isolated coal pillar. The conclusions are as follows:

(1) The filling mining model designed for isolated coal pillar has small disturbance on overlying strata and can implement isolated coal pillar mining with varied equivalent mining height. The measuring system designed for displacement at the surface of overlying strata can meet the requirements, but it still needs to be improved.

(2) The similar simulation method is able to judge the potential instability of the section coal pillar. As the equivalent mining height increases, the section coal pillar adjacent to large goaf will collapse in the first place. Thus, if the equivalent mining height is small, the deformation of section coal pillar is a key point that needs more focus. Otherwise, if the equivalent mining height is large, deformation of section coal pillar on two sides becomes the key point for monitoring.

(3) The equivalent mining height plays a vital role in the spatial evolution of overlying strata. When the equivalent mining height reaches up to a certain level, the fractures of overlying strata on isolated coal pillar interact with the original fractures of roof on goafs on two sides. The range and extent of roof will increase sharply, and the roofs on three goafs evolve into the structure of overlying strata formed by using caving method to mine isolated coal pillar.

(4) Using filling method to mine isolated coal pillar is expected to raise filling rate. The equivalent mining height should be restricted within a certain level, and tailgate should be set close to the small goaf. Reinforcing support is imposed on section coal pillar in mining working face to keep the stability of overlying strata.

(5) A further study on the spatial structure evolution of overlying strata with thick and hard roof and distribution of support pressure is expected to be carried out in the future and to perfect and upgrade the trial model, so as to explore the effects of filled goaf on the movement of high-level strata and distribution of advanced support pressure in working face.

\section{Data Availability}

The data used to support the findings of this study are available from the corresponding author upon request.

\section{Conflicts of Interest}

The authors declare that they have no conflicts of interest regarding the publication of this paper.

\section{Acknowledgments}

This work was supported by the National Natural Science Foundation of China under Grant nos. 51674014 and 51904017, Major Scientific and Technological Innovation Projects in Shandong Province under Grant no. 2019SDZY02, and Key Project of Natural Science Foundation of China under Grant no. 51634001.

\section{References}

[1] Z. Junfei, J. Fuxing, Y. Jianbo, B. Wushuai, and Z. Lei, "Rockburst mechanism in soft coal seam within deep coal mines," International Journal of Mining Science and Technology, vol. 27, no. 3, pp. 551-556, 2017.

[2] D. Li and J. Zhang, "Rockburst monitoring in deep coalmines with protective coal panels using integrated microseismic and computed tomography methods," Shock and Vibration, vol. 2020, Article ID 8831351, 10 pages, 2020. 
[3] M. Xiexing and Q. Minggao, "Research on green mining of coal resources in China current status and future prospects," Journal of Mining and Safety Engineering, vol. 26, no. 1, pp. 1-14, 2009.

[4] J. Fuxing, C. Gong, F. Yu et al., "Research on coal overall instability of isolated working face with irregular gobs on both sides," Chinese Journal of Rock Mechanics and Engineering, vol. 34, no. suppl 2, pp. 4164-4170, 2015.

[5] C. An-Ye, Z. Liang-Liang, L. Fu-Chen et al., "Characteristics of $T$-type overburden structure and tremor activity in isolated face mining under thick-hard strata," Journal of China Coal Society, vol. 39, no. 2, pp. 328-335, 2014.

[6] W. Hongwei, J. Yaodong, G. Renjie et al., "Evolution of energy field instability of island longwall panel during coal bump," Rock and Soil Mechanics, vol. 34, no. suppl 1, pp. 479-485, 2013.

[7] W. Jinhao, C. Weimin, C. Lianjun, S. Shaoshuai, and W. Zhijie, "A study of the dynamic movement rule of overlying strata combinations using a short-wall continuous mining and full-caving method," Energy Science and Engineering, vol. 7, pp. 2984-3004, 2019.

[8] Z. Minghua, J. Fu-xing, Z. Sitao et al., "Research and application of mining design based on prevention of rock burst under giant thickness hard strata," Journal of China Coal Society, vol. 44, no. 6, pp. 1707-1715, 2019.

[9] X.-X Miao and Z. Jixiong, "Analysis of strata behavior in the process of coal mining by gangue backfilling," Journal of Mining \& Safety Engineering, vol. 24, no. 4, pp. 379-382, 2007.

[10] Q. Zhang, J. Zhang, J. Wang, and P. Huang, "Theoretical research and its engineering practice on critical backfill ratio in backfill mining," Journal of China Coal Society, vol. 42, no. 12, pp. 3081-3088, 2017.

[11] Z. Jixiong, M. Xiexing, M. Xianbiao, and C. Zhongwei, "Research on waste substitution extraction of strip extraction coal-pillar mining," Chinese Journal of Rock Mechanics and Engineering, vol. 26, no. suppl 1, pp. 2687-2693, 2007.

[12] J. Kaijun, F. Guangming, L. Huajian et al., "Research on superhigh-water material filling mining in thin coal seam through similar simulation experiment," Journal of China Coal Society, vol. 38, no. supplement 2, pp. 267-271, 2013.

[13] Z. Junfei, J. Fuxing, Z. Sitao, and L. Zhang, "Width design for gobs and isolated coal pillars based on overall burst-instability prevention in coal mines," Journal of Rock Mechanics and Geotechnical Engineering, vol. 8, no. 4, pp. 551-558, 2016.

[14] W. Guangwei, "Research on theory and practice of mining legacy strip pillar with paste backfilling" Ph.D. thesis, China University of Mining \& Technology, Xuzhou, China, 2014.

[15] J-q. Jiang and B. Xu, "Study on the development laws of bedseparation under the hard-thick magmatic rock and its fracture disaster-causing mechanism," Geotechnical and Geological Engineering, vol. 36, no. 3, pp. 1525-1543, 2018.

[16] W. Zhijie, J. Suolin, J. Yujing, T. Lei et al., "Study of the fracture law of overlying strata under water based on the flowstress-damage model," Geofluids.vol. 2019, pp. 1-12, 2019.

[17] S. Atsushi and H. S. Mitri, "Numerical investigation into pillar failure induced by time-dependent skin degradation," International Journal of Mining Science and Technology, vol. 27, no. 4, pp. 591-597, 2017.

[18] D. Linming, C. Tongjun, G. Siyuan, H. He, and S. Zhang, "Rockburst hazard determination by using computed tomography technology in deep workface," Safety Science, vol. 50, no. 4, pp. 736-740, 2012.

[19] C. Shaojie, G. Weijia, Z. Hui et al., "Structure model and movement law of overburden during strip pillar mining backfill with cream-body," Journal of China Coal Society, vol. 36, no. 7, pp. 1081-1086, 2011.

[20] Z. Sitao, F. Yu, J. Fuxing, and J. Liu, "Mechanism and risk assessment of overall-instability-induced rockbursts in deep island longwall panels," International Journal of Rock Mechanics and Mining Sciences, vol. 106, pp. 342-349, 2018.

[21] Y. Weijian and W. Weijun, "Strata movement induced by coal-pillar under three circumstances exchanged by gangue backfill and quadratic stability law," Chinese Journal of Rock Mechanics and Engineering, vol. 30, no. 1, pp. 105-112, 2011.

[22] S. Xikui, Z. Qingmin, and S. Xianyuan, "Research and application on the technology of paste backfilling fully mechanized in residual strip pillar," Journal of Mining \& Safety Engineering, vol. 34, no. 4, pp. 650-654, 2017.

[23] L. Xuesheng, T. Yunliang, N. Jianguo et al., "Mechanical properties and damage constitutive model of coal in coal-rock combined body," International Journal of Rock Mechanics and Mining Sciences, vol. 110, pp. 140-150, 2018.

[24] S. Shilin, L. Xuesheng, T. Yunliang, D. Fan, Q. Ma, and $\mathrm{H}$. Wang, "Study on failure modes and energy evolution of coal-rock combination under cyclic loading," Shock and Vibration, vol. 2020, pp. 1-16, Article ID 5731721, 2020.

[25] F. Deyuan, L. Xuesheng, T. Yunliang, G. Qingheng, L. Yan, and X. Qiang, "Roof cutting parameters design for gob-side entry in deep coal mine: A case study," Energies, vol. 12, no. 10, pp. 2032-2056, 2019.

[26] F. Deyuan, L. Xuesheng, T. Yunliang, L. Yan, S. Song, and J. Ning, "An innovative approach for gob-side entry retaining in deep coal mines: A case study," Energy Science \& Engineering, vol. 7, no. 6, pp. 2321-2335, 2019.

[27] J. Zhang, D. Li, and Y. Wang, "Predicting tunnel squeezing using a hybrid classifier ensemble with incomplete data," Bulletin of Engineering Geology and the Environment, vol. 79, no. 6, pp. 3245-3256, 2020.

[28] Y. Sun, J. Zhang, G. Li et al., "Determination of Young's modulus of jet grouted coalcretes using an intelligent model," Engineering Geology, vol. 252, pp. 43-53, 2019.

[29] D. Li, J. Zhang, C. Wang, and F. Jiang, "Propagation patterns of microseismic waves in rock strata during mining: an experimental study," International Journal of Minerals, Metallurgy, and Materials, vol. 26, no. 5, pp. 531-537, 2019.

[30] J. Zhang, Y. Wang, Y. Sun, and G. Li, "Strength of ensemble learning in multiclass classification of rockburst intensity," International Journal for Numerical and Analytical Methods in Geomechanics, vol. 44, no. 13, pp. 1833-1853, 2020.

[31] D. Li, J. Zhang, C. Wang, Y. Chen, and D. Ge, "Assessing rockburst hazards using a self-developed real-time microseismic monitoring system in a deep-sea goldmine," IEEE Access, vol. 7, pp. 134360-134371, 2019.

[32] Y. Wei, Z. Qiang, H. Xiaole et al., "Overlying strata movement law and spatial structure analysis of fully mechanized mixed mining of backfilling and caving," Journal of China Coal Society, vol. 24, no. 2, pp. 388-396, 2017.

[33] Z. Baocheng, C. Congxin, L. Caihua et al., "Research in similar material of slope simulation experiment," Rock and Soil Mechanics, vol. 25, no. 11, pp. 1805-1808, 2004.

[34] L. dong, "Mechanism and control techniques of rockburst disasters in deep mines with thick topsoil and confined waterearing roof " Ph.D. thesis, University of Science and Technology, Beiijng, China, 2019. 